Public Health Nursing Vol. 3 No. 2, pp. 92-100

0737-1209/86/\$2.00

Copyright 1986 Blackwell Scientific Publications, Inc.

\title{
Health Behavior: Evolution of Two Paradigms
}

\author{
Shirley Cloutier Laffrey,* Carol J. Loveland- \\ Cherry, $\dagger$ and S. Joy Winklerł \\ *Assistant Professor of Community Health Nursing, School \\ of Nursing, University of Califomia, San Francisco \\ †Assistant Professor of Community Health Nursing, School \\ of Nursing, University of Michigan, Ann Arbor \\ $\ddagger$ Assistant Professor, School of Nursing, University of \\ British Columbia, Vancouver, B.C., Canada
}

\begin{abstract}
Public health nursing is a synthesis of professional nursing and public health science. To assist people effectively to determine and enhance their health capabilities, it is essential that public health nurses have a sound understanding of the behaviors that improve or jeopardize health. This concern arises from the profession's increased emphasis on health behavior and from nursing's stated goal of health promotion. To examine the topic from the perspectives of public health and professional nursing, we examine several issues related to the concept and its definition. We hope that the discussion will stimulate analysis both to clarify the concept and to contribute to the development of public health nursing science.
\end{abstract}

At present, public health nursing possesses a limited amount of research on which to base its practice. Because of this, public health nurses have not rigorously defined many of

Address correspondence to: Shirley Cloutier Laffrey, Assistant Professor, Community Health Nursing, School of Nursing, University of Califomia, San Francisco, CA 94143. Telephone: (415) 666-5213, 6661504.

This paper was adapted from a presentation at the annual meeting of the American Public Health Association, Montreal, Quebec, Canada, November 1982.

S. Joy Winkler, Ph.D., R.N. died suddenly in September 1985. the concepts that are integral to practice, leading to imprecision and inconsistency in their use. For example, health behavior is variously defined as (1) use of health care services, (2) compliance with medically prescribed regimens, (3) routine activities of one's life such as eating and sleeping, (4) actions taken to prevent illness, and (5) actions taken to achieve a higher level of well-being. These diverse definitions are frequently applied interchangeably, making it difficult to determine what is meant by the term. 
The paucity of research in public health nursing also has resulted in heavy reliance on knowledge from other behavioral sciences. Knowledge about health behavior has largely been derived from clinical medicine, sociology, and psychology. Examples are the major conceptual models used to explain why people do or do not engage in health behaviors. The most prominent, the health belief model, was developed in the mid-1950s by a group of social psychologists in the Public Health Service. The model represents a beginning theory to explain the widespread failure of individuals to accept preventive and early diagnostic measures against disease (Rosenstock, 1974). Two other models, social learning theory (Rotter, 1966) and the theory of reasoned action (Fishbein \& Ajzen, $1975)$, are also psychosociologic in origin. They are used increasingly in public health nursing to guide practice and research.

No doubt, continued development of public health nursing science will be facilitated by knowledge from fields related to nursing and public health. When we borrow information from other disciplines, however, it must be supportable by our professional frame of reference. Consequently, the health behavior models are applicable only if they are compatible with what we believe public health nursing to be. It is important that we have a clear understanding of the underlying premises on which the models are based when we apply them to practice and research.

Another source of knowledge used in public health nursing, common sense, frequently and appropriately becomes the basis for deriving problems for research study and for developing theory to guide practice. It must be articulated and developed, however, to be useful for these purposes. Hurley (1979) stated that common sense or intuitive beliefs are frequently marked by inconsist- encies and focus on isolated problems while failing to explore the relationships among problems. "Consequently, mutually inconsistent beliefs are frequently adopted as the basis for action" (p. 28). Inconsistencies in creating a structure for defining health behavior have particular significance for public health nurses as we increase the scientific base of knowledge for practice and research. The common sense and intuitive ideas about health behavior can be articulated and developed further. Gaps and logical inconsistencies will therefore be identified and can form the basis for research and theory development to guide public health nursing practice.

\section{GOALS OF PUBLIC HEALTH}

Goals and concerns of public health evolved from the social pressures and influences of the past. In the nineteenth century, the goal was to ensure adequate sanitation, thereby reducing health hazards with which individuals were thought to be powerless to cope. In the early to mid-twentieth century, public health was largely concerned with eradicating communicable diseases. Although efforts had expanded from control of the environment to preventive measures specifically aimed at the individual, human beings were still viewed as somewhat passive and impinged upon by the environment. Preventive measures were aimed at treating persons in such a way as to reduce the risk, or at least the severity, of illness should it occur despite such measures.

The latter half of the twentieth century has seen an expansion of public health concerns to include the complex relationships of physical and social environments. The Canadian government published $A$ new perspective on the health of Canadians (Lalonde, 1974) in which death and disease are incorporated 
into a health field concept comprising four elements: human biology, environment, personal lifestyle, and health care organization. Understanding the role of each of these elements can facilitate a course of action to increase health levels. These elements were discussed in the United States' Surgeon General's report (U.S. Dept. of Health, Education and Welfare, 1979) to assess their relative contribution to the 10 leading causes of death. It was determined that "perhaps as much as half of U.S. mortality in 1976 was due to unhealthy behavior or lifestyle" (p. 9). These two reports point to the need to shift emphasis from treating disease to preventing disease. Simultaneously, public health concern with disease prevention has broadened to include health promotion. There is increasing belief that health is a right of all persons, and that the individual not only has an active role in preventing illness, but assumes the primary responsibility for his or her own health. With this personal responsibility comes the right of the individual to choose behaviors that will be best suited to achieving health goals.

A word of caution is necessary here. The four elements are linked; personal lifestyle, including how one chooses to behave at any given moment, occurs within an environment that continually interacts with the individual. It is through this interaction that options and alternatives for behavior are perceived. It would be simplistic and dangerous to exhort individuals to adopt healthier lifestyles without considering the complex relationship that exists between them and their environment.

The complexity of the interaction between individuals and their environments was addressed by Milio (1982) with respect to forces for and against ceasing smoking among American women. She noted that short-term educational programs aimed at individuals are no match for the advertising power, political action, and national organization of the tobacco industry (p. 429) that result in a general climate of social desirability for smoking. To be effective in reducing smoking, efforts aimed at individuals must be supplemented by broader efforts directed to the community to change the climate in such a way that fewer options for smoking are perceived by the population.

The mandate for public health has shifted from acting in the public's behalf to helping the public to act in its own behalf. Consequently, there is increasing recognition of the need to understand the perceptions of the public about health and the mechanisms that facilitate health-promoting behavior. This includes recognizing that public perceptions about health and health behaviórs may not be synonymous with those of health professionals. Natapoff (1978) found that a group of children in grades one through seven held widely divergent views of what it means to be healthy. Earier, Baumann (1961) reported similar findings in a group of adult clinic patients and medical students. It is essential, therefore, that research attempt to identify these perceptions and beliefs in individuals and population groups before we can carry out significant interventions regarding health behavior.

\section{GOALS OF NURSING}

A stated goal of nursing is to promote human health. This goal has always existed in nursing and has become more prevalent in recent years (Ellis, 1982), being identified as a major concern of the profession (Donaldson \& Crowley, 1978). Considerable agreement exists among nursing leaders that the central concepts of the discipline are person, 
environment, health, and nursing (Fawcett, 1984). How these concepts interrelate determines nursing's focus and how this profession differs from others. Health behavior logically comprises the concepts person, health, and environment. Persons live in and constantly interact with their environments. Options and alternatives for behaviors present themselves within the environment and within the individual. People choose to behave in certain ways based on the range of options they perceive.

Patterns of health behavior choices were studied by Duffy (1984) with 59 femaleheaded, one-parent families. Health behaviors were a subset of the families' life circumstances and were a response to the societal options perceived as available. Three stages of behavior choice were identified. Choosing options was manifested by women who perceived severe barriers to health behaviors. Their behaviors were habits of long standing used as an attempt to secure a static environment or to escape from the environment or restore their depleted energy. Behaviors reported by this group included taking vitamins, smoking, and using drugs. The second stage, seeking options, expanded to include some experimentation with illnesspreventing and health-promoting behaviors and included new role definitions, moving to a new apartment, and developing a support system. Transcending options was manifested by women who perceived they had overcome their environmental barriers and were in control of their family's life circumstances. This group practiced healthpromoting and high-level wellness behaviors.

Health behavior is increasingly evident in the nursing literature as the scientific body of information becomes more clearly delineated. Clinical practice requires knowledge of health behavior to assist patients to attain their optimal levels of health, and research has generated data related to health behaviors and practices. Schlotfeldt (1979) urged basic studies to investigate health-seeking and health-risking mechanisms and behaviors. Theory development reflects the concem with health-related behavior as exemplified by Orem's (1980) self-care practices. Therefore health behavior logically fits within the scope of nursing and clearly has relevance for nursing research, whether basic or clinical, and for the refinement of scientific nursing knowledge.

According to Freeman and Heinrich (1981), public health nursing operates as a subsystem of health and human services and shapes its roles according to the expectations of society. Archer (1982) expanded on this idea, arguing that the public is demanding health services that are relevant to them and in which they can have an active role.

\section{CONCEPTUALIZATION OF HEALTH BEHAVIOR}

How one views person, health, and environment largely determines the way in which health behavior is defined. Two major paradigms for describing these concepts exist in the literature today (Fig. 1). From these, current definitions have been derived.

The first and most prominent is the pathogenic or disease paradigm that takes a mechanistic view of human beings and their behavior. The body is seen as machinelike, composed of parts that may or may not function smoothly. When a problem arises, diagnosis and treatment require the service of an expert practitioner. The patient is viewed as a passive, dependent, recipient of care who ideally accepts the treatment and complies with the practitioner's regimen to repair 


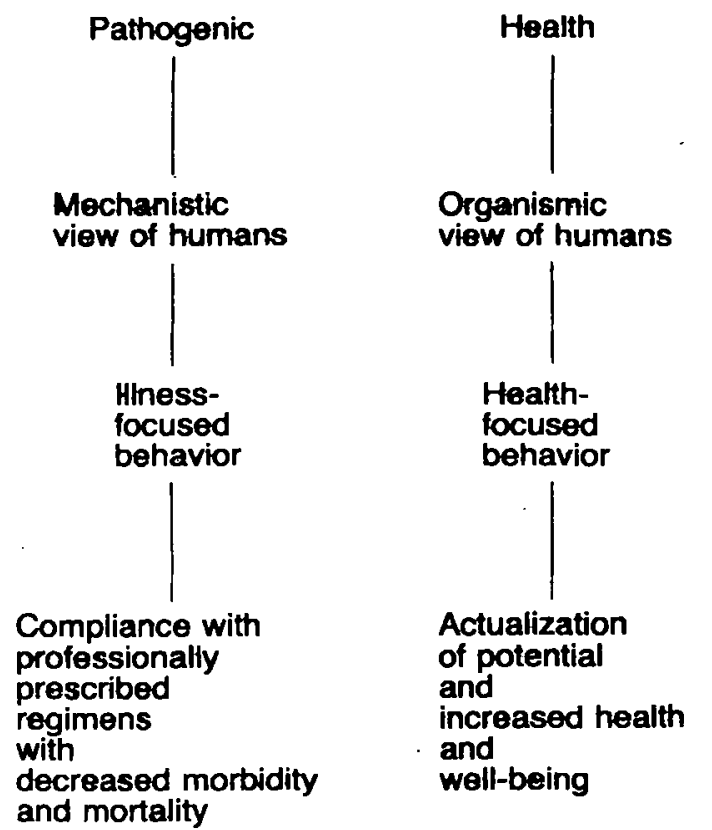

Flgure 1. Two major paradigms of health concopts.

the nonfunctioning body part. Because human beings are thought to react to stimuli in fairly predictable ways, their behavior reactions can be changed by manipulating stimuli in their environments. Interventions within the pathogenic paradigm are disease specific and efficient. Areas in which they are effective are screening programs, follow-up for medical care for specific diseases, and controlling epidemics.

The pathogenic paradigm views health as freedom from disease. Health behavior thus is any behavior that is disease related, whether it is to prevent or cure. This view of humans and health has been discussed at length (Hitt, 1971; Ferguson, 1980; Dossey, 1982).

Kasl and Cobb (1966) reflected the pathogenic paradigm in their definition of health behavior as "any activity undertaken by a person believing himself to be healthy for the purpose of preventing disease or detecting it in an asymptomatic stage." Pender's (1982) concept of health-protecting behavior as "directed toward decreasing the probability of encountering illness by active protection of the body against unnecessary stressors or detecting illness at an earty stage" also fits within this view. Steele and McBroom (1972) illustrated another dimension of the pathogenic model by considering preventive health behavior to be "the use of professional health services in an asymptomatic state with the emphasis upon behaviors that seek to avoid illness and its effects."

These three definitions reflect an adversarial person-environment relationship in which behavior reduces the effect of diseasecausing stressors from the environment. We suggest that public health nursing within the pathogenic paradigm logically would assess these stressors and then intervene to change the environment or the client's behavior (or both), with the aim of reducing the effect of the stressors on the person. The health behaviors best suited to this would be largely determined and prescribed by the public health nurse, and the success of nursing interventions would be determined by the degree of compliance with the prescribed behaviors and by reduction of morbidity and mortality. Presumably, if patients complied with treatment and rates of illness and death decreased in a given population group, health would have improved.

The second, health, paradigm represents a shift in perspective and is becoming increasingly evident in the literature (Antonovsky, 1979; Ferguson, 1980; Laffrey, 1985a; Schlotfeldt, 1979). It espouses an organismic view of human beings who are seen as autonomous, responsible, and having potential for growth. Humans are considered unique and unpredictable, able to exercise 
free choice in their actions. Health is a fluid, flexible process, a subjective phenomenon of each human being. Disease is not excluded in this view; rather it is part of the entire life process and may affect that process in various ways. The emphasis is not on any one part of the process but on the entire life situation of the individual. This view is consistent with Dunn's (1961) definition of health as maximum wellness oriented toward increasing the potential of which every individual is capable.

Within the health paradigm, persons do not merely react to environmental stimuli. They are self-determining and interact continuously with the environment, affecting it and being affected by it. The professional's role in health care consists not of repairing a nonfunctioning part but of assessing with the client the entire health situation and helping the client attain health goals that are personally relevant. Thus professionals and clients are partners in the process of promoting higher levels of health.

Harris and Guten's (1979) definition of health-protecting behavior as "any behavior performed by a person, regardless of his or her perceived or actual health status, in order to protect, promote, or maintain health, whether or not such behavior is objectively defined as effective toward that end," is transitional. It leans toward the health paradigm by acknowledging the autonomy of the individual and recognizing his or her values, and by accepting a partnership with health professionals. The emphasis on protecting health, however, is more congruent with illness orientation, as in the pathogenic paradigm.

Laffrey's (1985a, 1985b) definition of health-promoting behavior as that done primarily to increase one's level of health or well-being is derived from the health para- digm. According to Pender (1982), one's likelihood of engaging in a health-promoting behavior is affected by the importance one places on health, one's locus of control, desire for competence, degree of self-awareness and self-esteem, definition of health (actualization versus stabilization), health status, and perceived benefits from the health-promoting behavior.

Although health promotion and disease prevention are related and both are significant for nurses, the terms are not synonymous, and a degree of confusion surrounds their use. Health protection, according to Pender (1982, p. 65), is concerned with "decreasing the probability of encountering illness"; health promotion (1982, p. 65) is concerned with "sustaining well-being." Thus the terms are placed in the pathogenic and health paradigms respectively, but when one looks at definitions of protect and sustain (Random House College Dictionary, 1980), the differences between the words become obscure. Protect is "to defend or guard from attack, loss, insult" (p. 1063); sustain is "to undergo injury, loss, etc. without yielding" and "to help the mind, the spirits, etc. from giving way" (p. 1324). Despite a philosophical orientation toward health promotion, as exemplified by Pender (1982), current word usage in the health care system makes it difficult to distinguish between the pathogenic and health paradigms.

Definitions of health behavior in the health paradigm reflect a holistic view of the human being in constant and harmonious interaction with the environment. Public health nursing attempts to assess with clients what they consider as health and the behaviors they might undertake to promote health and well-being. Interventions are chosen by clients to assist them to promote higher levels of well-being. Because clients are unique and 
the behaviors are subjectively defined, evaluation is necessarily subjective. Clients themselves determine the degree of satisfaction and well-being achieved through the process of behavior.

No value or worthiness of one paradigm over the other is implied by the present discussion. Each has merit in appropriate situations. For example, in an epidemic, one needs efficient, short-term, disease-specific care. The pathogenic perspective can be used to advantage in meeting the goal of reducing or preventing illness. Screening and immunization programs also are instances in which this paradigm is effective and efficient. When the public health nursing goal is health promotion, however, it is limited, and a perspective is needed that moves beyond illness prevention to incorporate health promotion.

In the health literature both terms are used but more emphasis is placed on preventing illness. The Surgeon General's report (DHEW, 1979) clearly reflected this emphasis in the five major goals for the United States. Four of the goals specifically aimed at reduction of mortality and the fifth at major improvement in health, but continued to say that this will be achieved by a reduction of " 20 percent in the average number of days of illness among this age group" (p. $x$ ). The implication is that reducing mortality and morbidity means promoting health. This reflects the assumption that the terms are synonymous and is based on a definition of health as absence of disease.

For nurses, the restricted notion of health as absence of disease is unsatisfactory, but nurses have not been successful in developing an alternative definition (Ellis, 1982). Such can be arrived at only if we are clear and precise about the terms currently in use. For example, the health belief model (Hochbaum, 1983; Rosenstock, 1974) has been the basis of much health-related research. It postulates that an individual will be more likely to engage in a health behavior if he or she perceives susceptibility to a given disease, perceives the disease as serious, perceives that the health behavior will be beneficial in reducing the threat of the disease, and identifies no major barriers to engaging in the behavior. The model clearly derives from the pathogenic paradigm and is useful for predicting disease- or illnessrelated behavior. To use it to predict healthpromoting behavior is illogical, however, because the model is appropriate only if a threat is present. It is based on the assumption that health behavior is always triggered by some at least moderately strong fear of disease or accident and that it is basically preventive (Hochbaum, 1983). Health-promoting behavior requires a model that encompasses growth-producing motivations.

Society is in the midst of a major paradigm shift (Ferguson, 1980). It stems from Einstein's theory of relativity that superseded Descartes' view of separation of mind and matter and Newton's physics in which predictable mechanical forces were thought to explain phenomena. With this shift, our understanding of phenomena is moving from the "absolute to the relative" (p. 27). A new paradigm "includes the old as a partial truth, one aspect of How Things Work, while allowing for things to work in other ways as well' (p. 27).

Given Ferguson's arguments, we must replace the tendency to view health promotion as synonymous with, or a part of, illness prevention. From a public health nursing perspective, the goal is health promotion (American Nurses' Association 1974; Clemen, Eigsti, \& McGuire, 1981; Freeman \& Heinrich, 1981). If disease is viewed as only one among many potential manifestations of 
an individual in interaction with the environment and if health promotion is the goal, public health nursing seeks to assess the total health situation of the individual. Interventions are then directed toward increasing the total health situation. Increased health is manifested in many areas of the individual's life, some of which may be disease related. Thus the health model includes prevention of disease and illness but is not limited to this. The envisioned result is a greater scope of public health nursing practice leading to greater health and well-being above and beyond preventing disease.

\section{SUMMARY}

Health behavior has been examined relative to its basis in professional nursing and public health. The concept is central to public health nursing practice and research, and is clearly congruent with both professional nursing and public health. Two paradigms are evident in the literature, pathogenic and health. Each offers a different perspective within which health behavior is conceptualized and defined. The literature focuses mostly on the pathogenic paradigm and includes health promotion as one part of disease prevention. The general shift today is toward the health paradigm. An alternative view is that perhaps within the health paradigm, disease prevention can be incorporated, acknowledging that disease is one of a number of factors that might affect one's health; at the same time, noting that the scope of health is broader than the scope of disease.

In current use, the two paradigms have relevance in certain situations, but the combined model is more congruent with the aim of health promotion in public health nursing. It is important that public health nurses examine the perspective from which person, health, environment, and nursing are viewed. This will facilitate greater consistency in practice and research and, most important, will lead to further questions and discussion about health behavior, which in turn will promote greater clarification of this complex and important concept.

\section{REFERENCES}

American Nurses' Association. (1973). ANA standards, community health nursing practice. Kansas City, MO: Author.

Antonousky, A. (1979). Health, stress, and coping. San Francisco: Jossey-Bass.

Archer, S. E. (1982). Marketing public health nursing services. Paper presented at the American Public Health Association, Montreal, Canada.

Baumann, B. (1961). Diversities in conceptions of health and physical fitness. Joumal of Health and Human Behavior, 2(1), 39-46.

Clemen, S. A., Eigsti, D. G., \& McGuire, S. L. (1981). Comprehensive family and community health nursing. New York: McGraw-Hill.

Donaldson, S. K., \& Crowley, D. M. (1978). The discipline of nursing. Nursing Outlook, 26(2), 113-120.

Dossey, L. (1982). Space, time \& medicine. Boulder: Shambhala.

Duffy, M.E. (1984). Transcending options: Creating a milieu for practicing high-level wellness. Health Care for Women International, 5, 145-161.

Dunn, K. L. (1961). High-level wellness. Arlington, VA: R. W. Beatty.

Ellis, R. (1982). Conceptual issues in nursing. Nursing Outlook, 30(7), 406-410.

Fawett, J. (1984). Analysis and evaluation of conceptual models of nursing. Philadelphia: F. A. Davis.

Ferguson, M. (1980). The aquarian conspiracy: Personal and social transformation in the 1980s. Los Angeles: J. P. Tarcher.

Fishbein, M., \& Ajzen, I. (1975). Belief, attitude, intention and behavior: An introduction to 
theory and research. Reading, MA: AddisonWesley.

Freeman, R. B., \& Heinrich, J. (1981). Community health nursing practice (2nd ed.). Philadelphia: W. B. Saunders.

Harris, D. M., \& Guten, S. (1979). Health-protective behavior. An exploratory study. Journal of Health and Social Behavior, 20(1), 1729.

Hitt, W. D. (1971). Two models of man. In: D. L. Avila, A. W. Combs, \& W. W. Purkey (Eds.), The helping relationship source book. Boston: Allyn \& Bacon.

Hochbaum, G. M. (1983, November 14). The health belief model revisited. Paper presented at the annual meetings of the American Public Health Association, Dallas, Texas.

Hurley, B. A. (1979). Why a theoretical framework in nursing research. Westem Joumal of Nursing Research, 1(1), 28-41.

Kasl, S. A., \& Cobb, S. (1966). Health behavior, illness behavior, and sick role behavior. I. Health and illness behavior. Archives of Environmental Health, 12, 246-266.

Laffrey, S. C. (1985a). Concepts of health and health behavior. In S. E. Archer \& R. P. Fleshman (Eds.), Community health nursing. Monterey, CA: Wadsworth.

Laffrey, S. C. (1985b). Health behavior choice as related to self-actualization and health conception. Western Journal of Nursing Research, 7(3), 279-295.

Lalonde, M. (1974). A new perspective in the health of Canadians. Ottawa: Government of Canada.
Milio, N. (1982). Progress in primary prevention: The smoking-health issue. American Joumal of Public Health, 72(5), 428-429.

Natapoff, J. N. (1978). Children's views of health: A developmental study. American Joumal of Public Health, 68(10), 995-99.

Orem, D. E. (1980). Nursing: Concepts of practice (2nd ed.). New York: McGraw-Hill.

Pender, N. J. (1982). Health promotion in nursing practice. Norwalk, CT: Appleton-CenturyCrofts.

Random House College Dictionary (revised ed.). (1980). New York: Random House.

Rosenstock, I. M. (1974). Historical origins of the health belief model. Health Education Monographs, 2(4), 328-335.

Rotter, J. B. (1966). Internal versus external control of reinforcement. Psychological Monograph, 80(1), entire issue.

Schlotfeldt, R. M. (1979). Relevance of inquiryInquiry of relevance. (Midwestem Nursing Research Conference, Detroit, MI, May 8-9, 1979).

Steele, J. L., \& McBroom, W. H. (1972). Conceptual and empirical dimensions of health behavior. Joumal of Health and Social Behavior, 13, 382-392.

U.S. Department of Health, Education and Welfare. (1979). Healthy people: The surgeon general's report on health promotion and disease prevention. (DHEW (PHS) Publication No. 79-55071). Washington, DC: U.S. Government Printing Office. 